\title{
Italian research
}

\section{New president's ambitions firm and unclouded}

\section{Rome}

Professor Luigi Rossi Bernardi, the respected haemoglobin physiologist who is the new president of the Italian national research council (CNR), is moving like a whirlwind through the dusty corners of this dominant institution of publicly-funded science in Italy. But some old hands are already wondering whether the wind will really clean up the moribund organization or merely raise dust.

Whatever the outcome, the new president is starting as he means to go on not least by introducing real (if presently crude) measures of output and scientific quality into the CNR system, where many groups and projects, critics say, are continued long beyond their useful life. Thus, within days of his appointment, Rossi Bernardi obtained tapes of world publications and citations from the Institute for Scientific Information in Philadelphia, and began analysing them on a computer in Milan for the publications of CNR groups and institutes.

The analysis took a week of computer time, but threw up results such as that some ten CNR groups or institutes (out of 270) had published nothing for five years. Such groups will be closed, Rossi Bernardi promises.

And at an extraordinary meeting last week in Rome, nominally to present the annual report to the assembly of CNR which was in practice the new president's first chance to present his policies publicly, these policies were alternatively vigorously supported, barely criticized and finally approved. According to one enthusiast who spends half his time at the USNational Institutes of Health, the occasion was fundamental in that it represented a thorough changing of the old guard.

As if to emphasize the political nature and certainly the importance of the task ahead, Rossi Bernardi was flanked throughout last week's meeting by the minister of research, Mr Luigi Granelli, who seems at least as determined as his new CNR president to change the face of Italian science. It was the first time in the memory of some observers that a minister had spent so long at a CNR meeting - which ran into a second day, with a seminar on the international relations of the council. In that half of the meeting, distinguished Italian scientists working abroad presented their comparisons of foreign (often American) procedures with those in Italy, thus - inevitably - lending weight to Rossi Bernardi's own proposals. Italian science attachés from Washington, Moscow and elsewhere were also afforded their own time for criticisms. Rossi
Bernardi later made some "quite exciting proposals", according to one attaché, for the revitalization of the attaché network thus emphasizing the importance the new CNR president attaches to avoidance of parochialism.

Granelli also pledged himself to removing the "parastatale" status of the CNR, which equates CNR scientists with the meanest of Italian civil servants, and whose effect is to make promotion entirely dependent on age. He also estimated present Italian research and development spending as 1.3 per cent of gross national product (it was under 1 per cent at the end of the 1970s), and set a target of 2.5 per cent by the end of the 1980 s. There was a 40 per cent increase in public spending on science in Italy last year, it was claimed.

Rossi Bernardi's objectives for 1985 include:

- Decentralization.
- Cutting a tangle of red tape and obscurity in CNR financial management, including a new separation of administrative and research expenditure.

- Setting up a databank on CNR personnel.

- Monitoring scientific output.

- Better control of the "finalized projects" (through which, in practice, many university groups raise funds for only nominally applied research projects).

According to the minister of research, such reform is necessary not only for CNR, but should act in CNR as a "nucleus" for the reform of science in all Italy.

All stirring stuff - but some sceptics in Rome last week felt the momentum would finally dissipate in the treacle of Italian bureaucracy, while others felt Rossi Bernardi to be well-meaning but politically naive in a country where politics is all. Granelli, who is strongly behind the new CNR president's initiatives, may also not last long - few Italian ministers do, as governments fall frequently, or he may be promoted - when Rossi Bernardi may find himself exposed and rather alone. But as Granelli himself said last week, Italy faces "marginalization" if research is not taken in hand.

Robert Walgate

\section{Reducing grant-writing burden}

\section{Washington}

THE US National Institutes of Health (NIH) are to consider extending the durations of their extramural research project grants in order to reduce the burden of preparing grant applications and to provide reviewers with better evidence on researchers' peformance. This general proposal was well received at a meeting last week of the NIH director's advisory group, and NIH director James Wyngaarden said after the meeting that he took the favourable response as an "endorsement in principle" for extending grants to firsttime applicants beyond the usual 3 years. Grants to mid-career and distinguished investigators might also be extended.

The move comes in response to growing concern in the academic community that the pressures created by the system as at present operated - termed "intimidating" by Wyngaarden - are impeding research creativity. Most first-time grant holders must start preparing renewal applications after less than 18 months' work - hardly enough time for a realistic appraisal of progress. Furthermore, researchers often spend up to three months drafting applications, because most believe, probably correctly, that their chances of a renewal depend on the result of a detailed scrutiny of the proposal.

Several invited participants from academic institutions last week urged a return to the philosophy of investment in promising scientists, rather than "procurement research". There was dissatisfaction that "study groups", the first level of peer review for grant applications, spend too much effort examining minutiae and "micro-managing" projects. Many suggested that reviewers would be able to make more informed judgements if most firsttime grants were to be extended to, say, five years. One proposal that Wyngaarden found attractive was that grants might specify a fixed amount of money that could then be spent over a longer or shorter period depending on progress. This solution might allay the anxiety of having to produce results within three years, while avoiding substantial extra commitments on the NIH budget. However, no formal vote was taken, and Wyngaarden stresses that any change to present practice will first be subject to internal review.

Dr Joshua Lederberg, president of Rockefeller University and a leading critic of present practice, said it was not yet clear how any change should be implemented, and stressed the need for more information on the careers of those who fail to obtain grant renewals and disappear from NIH records. Academic institutions are becoming less able to find alternative work for such people, and the average duration of tenure of a trained researcher within the extramural system is only seven years, which Lederberg thinks represents a wasted investment. Reviews emphasizing the track record of the applicant would, he feels, bring much-needed stability to the careers of mid-term investigators.

Tim Beardsley 